\title{
LOS CONSORCIOS DE EXPORTACIÓN: REVISIÓN CONCEPTUAL Y FACTORES DETERMINANTES DE ÉXITO
}

\section{EXPORT CONSORTIA CONCEPTUAL: REVISION AND DETERMINANT FACTORS OF SUCCESS}

\author{
Espejo León, Álvaro (Universidad de Córdoba) * \\ Fuentes García, Fernando (Universidad de Córdoba) *** \\ Núñez Tabales, Julia (Universidad de Córdoba) ${ }^{* * *}$
}

\section{RESUMEN}

El asociacionismo lleva implícito multitud de fórmulas de cooperación entre empresas, dando lugar a diversos conceptos que en ocasiones pueden ser muy distintos entre sí y, en otras, se diferencian por escasos o pequeños matices. Dentro de este contexto y de las distintas opciones de asociación de empresas que existen -tanto en origen como en destino-, es oportuno abordar la fórmula de consorcio de exportación, realizando un análisis para aclarar el concepto y diferenciarlo de otras modalidades con cierta similitud. Se trata de una vía de acceso a mercados, apropiada para las pymes, que carece de estudios de investigación de casos reales y que necesita de los mismos, ya que hoy en día vuelve de nuevo a ponerse de relieve. El trabajo que aquí se presenta tiene como objetivo hacer una revisión de la literatura existente, tanto teórica como de estudio de casos, que sirva de recopilatorio para una posterior investigación empírica. En el trabajo se busca las siguientes aportaciones o resultados principales: ofrecer una concepción evolucionista del concepto de consorcio de exportación, recabar los principales factores determinantes que llevan a la empresa a salir al exterior bajo esta fórmula, analizar lo que hay publicado sobre la pervivencia en el tiempo de los consorcios de exportación, dar luz sobre los distintos tipo de consorcios de exportación que existen y realizar una recopilación de los principales factores determinantes del éxito o del fracaso de este modalidad asociativa.

Palabras claves: Cooperación empresarial, consorcios de exportación, internacionalización, exportación. JEL: A10, M10, M21.

\footnotetext{
ABSTRACT

Associationism is composed by different ways of cooperation between companies. It can be reflected because of a variety of concepts which are not similar between them. Sometimes, those concepts are differentiated by slight nuances and sometimes, they do not. Paying attention to the concept and to the dissimilar ways of companies' association is indispensable not to address to export consortium as a formula. The work presented here aims to make a review of the existing literature, both theoretical and case study that serves as a compilation for further empirical research. At work the following main findings contributions or wanted: provide an evolutionary interpretation of the concept of export consortium, gathering the

* Departamento de Organización de Empresas, Facultad de Derecho y Ciencias Económicas y Empresariales, 14071, Puerta Nueva s/n, Córdoba. d42eslea@uco.es

** Departamento de Organización de Empresas, Facultad de Derecho y Ciencias Económicas y Empresariales, 14071, Puerta Nueva s/n, Córdoba.el1fugaf@uco.es

*** Departamento de Organización de Empresas, Facultad de Derecho y Ciencias Económicas y Empresariales, 14071, Puerta Nueva s/n, Córdoba.es2nutaj@uco.es Recibido: Septiembre de 2015. Aceptado: Diciembre de 2015.
} 
main factors that lead the company to go abroad under this formula, analyze what is published on the survival in the time of export consortia, shed light on the different types of export consortia exist and a compilation of the major determinants of success or failure of this form of association.

Key words: Business partnership, export consortia, internationalization, export. JEL: A10, M10, M21.

\section{APROXIMACIÓN AL CONCEPTO DE CONSORCIO DE EXPORTACIÓN}

El desarrollo de políticas exportadoras comprometidas comporta la movilización de unos recursos que las empresas pueden no estar en condiciones de asumir. Además, no todas ellas tienen todos los recursos necesarios para ser diferenciadores o actuar eficazmente en un mercado exterior, lo que conlleva la búsqueda de sinergias o colaboraciones, una especie de teoría de la ventaja comparativa entre países aplicada a las empresas (Castro González, 2010). Las acciones colectivas están basadas en el argumento de que los individuos tienen necesidades comunes que sólo pueden ser satisfechas por medio de la acción conjunta. Según Fernández (1991), el funcionamiento de la cooperación se sustenta sobre la base de relaciones privilegiadas o acordadas, establecidas entre empresas y sus competidores o entre esta y otras de su entorno. Añade Errecart (2013) que el objetivo final es minimizar, a través de los acuerdos de cooperación, los costos de transacción.

En primer lugar, es importante diferenciar entre consorcio en origen y en destino. Para esta distinción se toma de referencia a López Navarro y Camisón (1999) en el que su estudio añade una variable clave: la localización de las actividades del grupo. Así, se mencionan casos donde el consorcio se constituye y actúa en el país de origen de las empresas que lo conforman, actuando como un centro de exportación compartido - consorcio en origen-; casos en los que el consorcio se constituye en el mercado foráneo objeto de actuación consorcio en destino - , actuando como una red de distribución propia en el exterior e incluso se habla del consorcio en destino como una filial de ventas (López Navarro, 2001).

\section{GRÁFICO 1: MODELOS CONSORCIALES DE ACUERDO CON LA LOCALIZACIÓN DE LAS ACTIVIDADES DEL GRUPO}

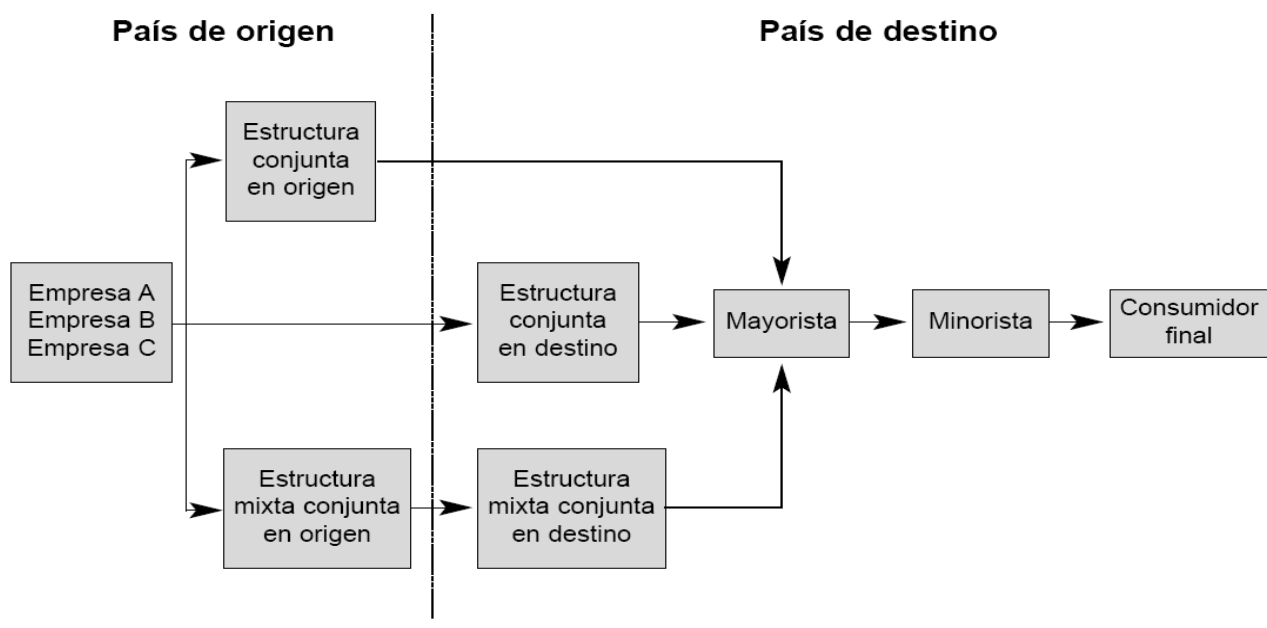

Fuente: López Navarro (2001: 143-168) 
Dentro de la revisión de la literatura que se realiza para la aproximación conceptual, se comprueba que se han venido utilizando diferentes términos para referirse a los modelos de exportación agrupada en origen, tales como alianzas o acuerdos estratégicos (Renart, 1999; Castro González, 2010), consorcios de exportación (Lanzara, Varaldo y Zagnoli, 1991; Castro y Moneu, 1993; Renart, 1996; Renart 1999), grupos de exportación (Welch y Joynt, 1987; Renart 1999; Barcenillas 2013), consorcios de exportación enfocados (CEXEN) (Renart 1999) o «joint-ventures» para la exportación (Bradley, 1985; Gebhard, 1987).

Es interesante, por tanto, aclarar a continuación el concepto de cada uno de los términos relacionados, centrándose el estudio en la asociación formada en origen, lo que permitirá esclarecer sus diferencias.

\subsection{Alianzas estratégicas}

La alianza ha tenido multitud de definiciones siendo las aquí recogidas, tras la revisión de la literatura, las siguientes: alianza como cooperación entre empresas que trabajan juntas para alcanzar algún objetivo estratégico (Berg et al., 1982; Harrigan, 1988); enfatizando diversas características, tales como que, generalmente, incluyen a dos o más empresas unidas en busca de una serie de objetivos acordados (Zhao et al., 2007); que contribuyen de manera complementaria con sus capacidades específicas; que se implican en una serie de tareas y actividades interdependientes (Contractor y Lorange, 1988), en la que sólo se puede ejercer un limitado control por las partes (Gomes-Casseres, 1994); y que mantienen en paralelo su independencia como empresas y comparten los riesgos y beneficios de la cooperación (Zhao et al., 2007).

Buscando otra definición genérica, de un autor de referencia cuando se habla de alianzas empresariales se encuentra a Renart (1999): "Una alianza estratégica es un acuerdo voluntario de colaboración, a medio y largo plazo, entre dos o más empresas independientes, al objeto de llevar a cabo de manera coordinada ciertas acciones para conseguir ciertos resultados." Como se puede extraer de la definición, la explicación tiene un cariz genérico, lo que lleva a la posibilidad de entender las restantes modalidades objeto de estudio como desarrollo de este concepto. Por ejemplo, Barcenillas (2013), habla de la alianza como una fórmula global, amplia y que encaja con el planteamiento de los denominados grupos de exportación, que más adelante serán definidos.

Esta definición también da lugar a incluirle multitud de alianzas estratégicas que se pueden dar con empresas tanto nacionales como internacionales como por ejemplo: uniones temporales de empresas, acuerdos de piggy-back, firmas de acuerdos de cesión tecnológica, acuerdos con distribuidores y/o importadores, etc.

Se hace referencia, por tanto, a un acuerdo de colaboración, formalizado en la mayoría de las ocasiones por un contrato, con un vencimiento definido en el tiempo y donde se conserva los propios órganos de gobierno sin perder su personalidad, ni crear otras personalidades jurídicas. Sus acuerdos suelen ser más sencillos, más ágiles y con menos trabas legislativas, por tanto, las rupturas suelen ser más fáciles, más rápidas y menos traumáticas. Igualmente y como se ha señalado anteriormente, muchas de las otras fórmulas a estudiar, surgen o tienen su principio en alianzas estratégicas, donde sirven de fase previa para validar la relación o como atractivo para que nuevas empresas se unan en una nueva figura.

\subsection{Grupo de exportación}

El concepto de grupo de exportación es un concepto nuevo, que años atrás no existía y que se puede decir que nace a través de líneas de apoyo que lanzaron las instituciones 
públicas encargadas de promover las exportaciones a nivel nacional y autonómico. Para más detalles el programa se lanzó en Andalucía tras la realización del I Foro de Consorcios de exportación. De dicho foro surgieron las ideas que inspiraron el citado programa, con fórmulas más flexibles para las empresas.

Según Barcenillas (2013) los grupos de exportación son "la alianza de empresas, en número de tres a siete, que trabajan juntas en la construcción de la relación grupal y en la definición de un modelo propio de cooperación, sus objetivos, estrategia y plan de acción."

Es importante resaltar aquí varios aspectos clave como: el número de empresas está cerrado y delimitado entre 3 y 7 socios lo que evidencia una diferenciación clara con otros conceptos; también se hace referencia al trabajo conjunto, o coordinado para crear y construir relaciones grupales, algo que se resalta como finalidad; y, por último, se menciona la preparación de un modelo definido con objetivo, estrategias y planes de acción. Es decir, el grupo es una alianza de empresas que busca preparar y delimitar un modelo con el único objetivo de construir unas sólidas relaciones entre los integrantes y un proyecto para en fases posteriores llevarlo a ejecución. Los grupos de exportación surgieron, por tanto, como fórmula flexible, a modo de preconsorcio, sin que se requiriera en ellos una fórmula jurídica independiente, como ocurre con los consorcios de exportación.

\subsection{Joint venture}

La joint venture es una forma más conocida y una de las más usadas cuando se habla de acuerdos entre empresas. Sánchez de Pablo (2007) lo definía como un "acuerdo de capital" donde existen participaciones en el capital social de las empresas implicadas; mientras que para los consorcios habla de "acuerdos contractuales", ya que regulan la relación de los socios mediante un contrato.

La joint venture se define como acuerdo de cooperación estructurado, a través del cual dos o más empresas llegan a un acuerdo accionarial, por el que se crea una nueva entidad para la realización de proyectos conjuntos pero sin llegar a formar una filial. Otra diferencia es la apuntada por García Canal (1996), donde la entidad es legalmente independiente de los socios, pero es propiedad de éstos, siendo responsable de la coordinación de las actividades que implica acuerdos colaborativos. Además, se generan compromisos duraderos e irreversibles entre los socios, ya que requiere de la aportación de un número considerable de recursos (Gulati y Wetphal, 1998). Esta asociación empresarial trae consigo el establecimiento de jerarquías administrativas, donde se realiza el control y la coordinación del resultado de las actividades implicadas en la alianza y la participación de los socios en el resultado de la empresa en función al porcentaje. El sistema de incentivos es más eficaz que en el resto de formas organizativas, ya que todos los socios conocen el valor de su capital.

\subsection{Consorcio de exportación}

La cooperación inter-empresarial de pymes permite a las empresas por separado mejorar su competitividad y con ello aprovechar oportunidades que surgen en los mercados internacionales como consecuencia de la globalización. Los consorcios de exportación, para Errecart (2013,) son ejemplos vívidos de ese tipo de cooperación inter-empresarial, son un elemento natural de una estrategia de desarrollo de conglomerados y redes.

Las definiciones de este concepto son múltiples, existiendo algunas de carácter más general como la de Ullmann (1999): "asociación permanente de empresas, cuyo objetivo principal es agrupar ofertas de productos o servicios nacionales y demandas de productos o servicios del exterior”. Para Sánchez de Pablo (2007) el consorcio de exportación es un 
"acuerdo contractual donde se recogen los condicionantes del mismo, pese a tener una forma estructurada al igual que las empresas conjuntas. No se crea una nueva empresa, pero sí que existe una organización de nivel superior con un horizonte temporal cierto, en la que participan miembros de los distintos socios, encargada de coordinar la empresa, tomar decisiones conjuntas y asignar aportaciones y tareas a realizar a cada socios.". Por su parte, Renart (1999) define un consorcio de exportación como un "acuerdo voluntario de cooperación entre dos o más empresas, al objeto de desarrollar conjuntamente sus mercados exteriores. Un consorcio de exportación es, pues, un tipo o caso particular dentro del universo más amplio de las alianzas estratégicas entre empresas".

Pero aunque se haya precisado su objetivo estratégico -el exportar en equipo-, las dificultades derivadas de la variedad de tipologías subsisten por cuanto en la realidad y en la bibliografía se encuentra que existen consorcios de exportación en origen y en destino; de promoción comercial y de venta; consorcios monosectoriales y multisectoriales; $\mathrm{o}$ clasificables en función de su ámbito geográfico de origen de sus empresas socio o de preferente actuación comercial, etc. (Castro y Moneu, 1993).

Errecart (2013) apunta que "un consorcio de exportación es una alianza voluntaria de empresas con el objetivo de promover los bienes y servicios de sus miembros en el extranjero $y$ de facilitar la exportación de sus productos mediante acciones conjuntas". El autor relaciona a estos consorcios con tres conceptos que van íntimamente relacionados: "acciones colectivas, la cooperación entre empresas y las redes empresariales". Además, añade que el objetivo, entre otros, es "reducir los costos de internacionalización", en otras palabras, los costos de transacción inherentes al proceso exportador. Para López Navarro (1999) un consorcio de exportación "en un sentido amplio, se concreta en la unión de una serie de empresas para constituir una entidad conjunta, jurídicamente independiente, que se encargue de desarrollar y coordinar, total o parcialmente, su actividad exportadora en uno o varios mercados exteriores". Añadiendo López Navarro (2001) que ello supone la coordinación, por parte de las distintas empresas implicadas en la relación, de uno o más aspectos de su actividad de marketing internacional -función origen de la colaboración-, si bien ésta podría extenderse a otras actividades previas tales como investigación, desarrollo de productos e incluso producción.

Se trata, por tanto, de acuerdos de cooperación de carácter horizontal, que responden a la lógica de facilitar determinadas actividades o funciones empresariales, aunque en este caso su ámbito se circunscribe a la actividad comercial en el campo internacional, a la vez que posibilitan la obtención de ventajas en las relaciones verticales con los canales de distribución (Reve, 1990 y 1992). A pesar de que este último autor habla de acuerdos de cooperación de carácter horizontal, hay autores que también hablan de la posibilidad de consorcios de exportación verticales como López Navarro (2001) y Barcenillas (2013).

Por último, para Barcenillas (2013) el consorcio de exportación es "el que confirma su proyecto y asume compromisos formales, constituyendo normalmente una nueva organización, con entidad jurídica propia e independiente de las de los socios miembros del consorcio". En concreto, se refiere a que el consorcio de exportación es la confirmación y ejecución, es decir, el grupo de exportación puede considerarse como preconsorcio con menor compromiso hasta que la comunicación y confianza conduzcan a sus miembros a integrar y formalizar sus aportaciones en el consorcio. Por tanto, buscan cooperar en un ámbito más reducido de colaboración, en pocas áreas funcionales. Ejemplos de ello serían, grupo de compra, grupo expositor, publicidad compartida, gestores a tiempo parcial compartidos, entre otros posibles. A medida que aumenta el compromiso y el grupo va formalizando su 
compromiso, el ámbito va normalmente ampliándose también, dando lugar a consorcio de exportación.

Los grupos de exportación o cooperación son utilizados durante la fase de construcción interna y planificación y, luego, llamamos consorcios de exportación, una vez asumidos y formalizados los compromisos asociados al proyecto de cooperación definido en grupo. El proceso de compromiso, medido como grado de integración y formalización que los miembros de un grupo o consorcio de exportación dan a su relación, determina la forma de éstos.

Finalmente, es conveniente resaltar un aspecto importante y que siempre crea dudas y existen opiniones diversas, como es el de si el consorcio de exportación lleva a crear una entidad jurídica independiente. Así, Sánchez de Pablo (2007) no habla de crear nuevas formas jurídicas, sino que apunta que las empresas adoptan un compromiso de cooperación comercial entre ellas y son los mismos miembros del consorcio quienes determinan normas que regulan lo que cada empresa aporta al consorcio, así como también los respectivos deberes y derechos. Errecart (2013), por su parte, tomando como referencia otras definiciones llega a la conclusión de que el rasgo distintivo de esta modalidad de cooperación, es que de la unión no surge una fusión de empresas, sino que participan en la formación de una nueva organización con la que concretan un acuerdo comercial conservando cada empresa individual su personalidad propia como productora y manteniendo su estructura específica de administración. A ellos se unen Cabeza y Martínez (2004), que apuntan que la nueva organización que resulta de la iniciativa de cooperación entre las empresas no se constituye en una nueva persona jurídica desde un punto de vista estrictamente legal. En cambio se convierten en organizaciones que actúan de manera informal, es decir, no constituyen una nueva sociedad. Por último, y en esta misma línea ONUDI (2004) hace referencia a que los miembros de un consorcio de exportación conservan su autonomía financiera, jurídica y de gestión. Esto constituye la diferencia principal entre los consorcios y otros tipos de alianzas estratégicas. Aunque defiende esta línea de pensamiento, pero añade que pueden agruparse en "una entidad jurídica separada" que no implica la pérdida de identidad de ningún miembro. De esta manera, aclara que un consorcio difiere de una fusión en el sentido de que todas las empresas participantes conservan su condición jurídica inicial y la administración de cada empresa conserva su independencia.

En el otro punto de vista, se encuentran varios autores. Así, López Navarro (1993) menciona explícitamente la creación de una nueva forma jurídica, Barcenillas (2013) expone que normalmente se crea una nueva forma jurídica. En esta línea va Martínez Cardazo (2003) que, basándose en una entrevista a técnicos de comercio exterior de Cámaras de Comercio que han trabajado en programas de formación de grupos de exportación, señala que los consorcios de exportación no llegan a tener la personalidad jurídica independiente, llamándoles pre-consorcios -son los grupos de exportación que menciona Barcenillas (2013)-, porque sirven para empezar a colaborar en un mercado. Por último, puede formarse o no una nueva entidad jurídica diferenciando según tipo de consorcios; los consorcios promocionales suelen ser formados con un contrato, mientras que los de ventas sí suelen llevar a nueva forma jurídica.

\subsection{Consorcio de exportación enfocado}

Dentro de los consorcios de exportación existe un tipo de consorcio de exportación enfocado (cexen) que tiene algunas características que le hacen particular. Es un subtipo concreto de consorcios de exportación (Renart, 2002). Un Cexen ha sido definido en Renart 
(1999, 2002) basándose en nueve características concretas del Cexen en sí mismo, o de las empresas- socio que lo componen:

- Tiene menos de 10 empresas-socio.

- Tiene un período de duración indeterminado en el momento de su constitución formal.

- Puede ser un consorcio en origen o en destino.

- Es una alianza horizontal, es decir, que no hay relaciones significativas de tipo proveedor-cliente entre las empresas-socio.

- Las empresas-socio son independientes entre sí, es decir, que no hay posiciones de dominio accionarial de unas sobre otras, ni socios dominantes comunes.

- Las empresas-socio comercializan productos o servicios diferenciados (no genéricos).

- Las empresas-socio tienen un tamaño y una importancia similar, es decir, que ninguna de ellas disfruta de una posición privilegiada de poder o dominio sobre las demás a consecuencia de su gran tamaño, o por tener unos productos o una marca líder, etc.

- Las empresas-socio adquieren un grado de compromiso comercial, económico y social relativamente elevado.

- Las empresas-socio están dispuestas a diseñar y a poner en práctica una estrategia comercial de exportación común (es decir, que no se limitan a llevar a cabo ciertas acciones de promoción).

\section{GRÁFICO 2: LA ASOCIACIÓN EMPRESARIAL EN FUNCIÓN DE SU ORIGEN}

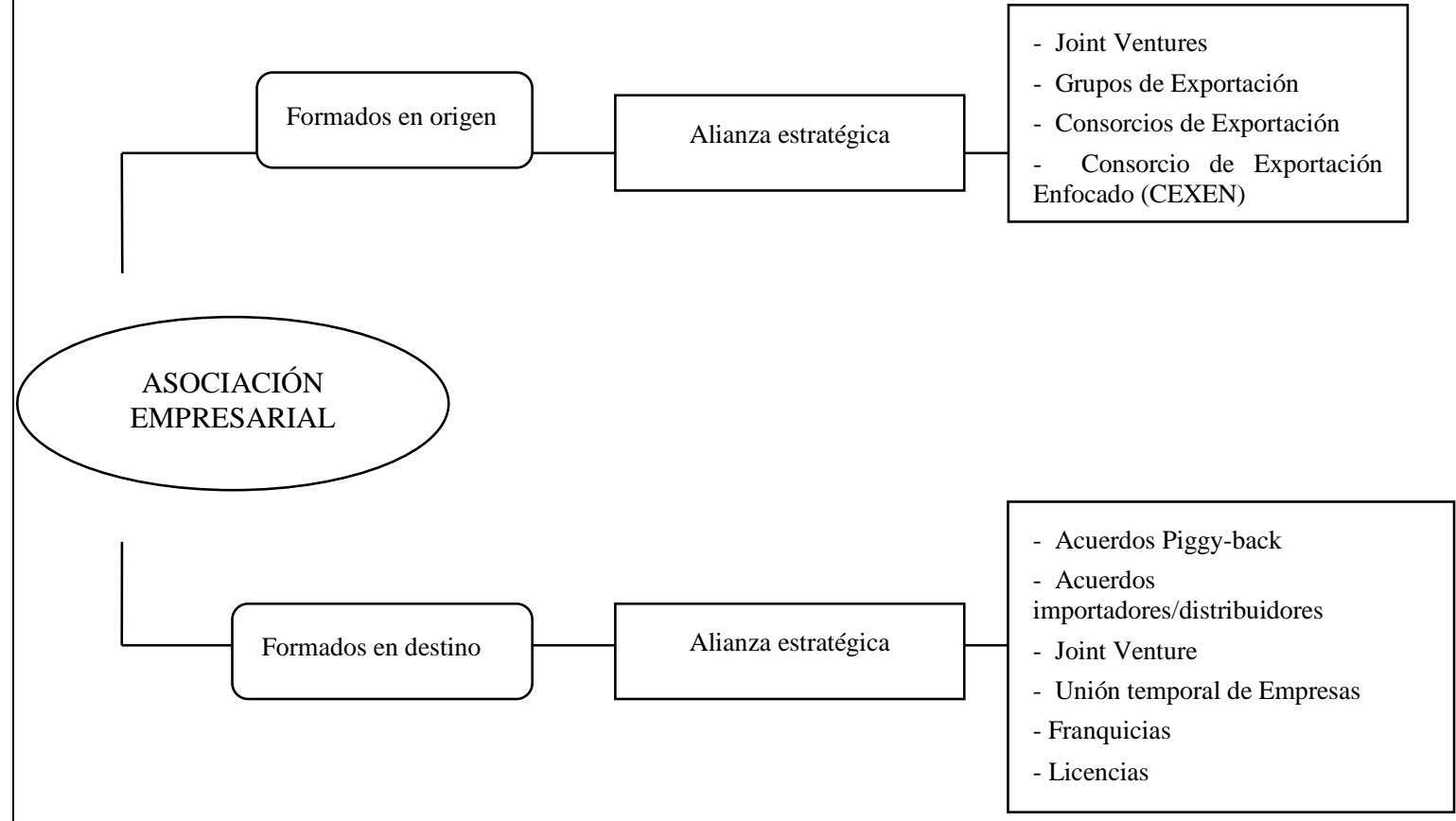

Fuente: Elaboración propia

En el cuadro 1 se resumen los cinco conceptos analizados como asociaciones empresariales para la salida a mercados exteriores. Se han tomado hasta ocho variables que ayudan a definirlo y especialmente a distinguir los diferentes términos: el horizonte temporal para los que están definidos, el número de empresas que normalmente lo forman, si es 
necesario sistemas de coordinación para su buen funcionamiento, el tipo de acuerdo necesario, el tipo de relaciones que existe entre empresas que lo forman, el vencimiento para el que está creado esa asociación, si se crea una nueva personalidad jurídica y los objetivos generales para los que han sido definidos.

\begin{tabular}{|c|c|c|c|c|c|c|c|c|}
\hline \multicolumn{9}{|c|}{$\begin{array}{l}\text { CUADRO 1: CARACTERIZACIÓN DE LAS DISTINTAS FORMAS DE } \\
\text { ASOCIACIÓN EN ORIGEN }\end{array}$} \\
\hline & $\begin{array}{l}\text { Horizonte } \\
\text { temporal }\end{array}$ & $\begin{array}{c}\mathbf{N}^{\circ} \\
\text { Empresas }\end{array}$ & Coordinación & $\begin{array}{c}\text { Tipo de } \\
\text { Acuerdo }\end{array}$ & $\begin{array}{l}\text { Tipo de } \\
\text { relaciones }\end{array}$ & Vencimiento & $\begin{array}{l}\text { Personalidad } \\
\text { jurídica }\end{array}$ & Objetivos \\
\hline $\begin{array}{l}\text { Alianzas } \\
\text { estratégicas }\end{array}$ & $\begin{array}{c}\text { Medio/ } \\
\text { Largo plazo }\end{array}$ & 20 más & Sí & $\begin{array}{c}\text { Capital y } \\
\text { contractual }\end{array}$ & $\begin{array}{l}\text { Horizontal } \\
\text { y vertical }\end{array}$ & Limitado & No & $\begin{array}{c}\text { Consecución } \\
\text { de cualquier } \\
\text { resultado } \\
\text { empresarial }\end{array}$ \\
\hline $\begin{array}{l}\text { Grupo de } \\
\text { exportación }\end{array}$ & Corto plazo & De 3 a 7 & Sí & Contractual & $\begin{array}{c}\text { Horizontal } \\
\text { y vertical }\end{array}$ & Limitado & No & $\begin{array}{c}\text { Crear } \\
\text { relación } \\
\text { grupal, } \\
\text { definir } \\
\text { modelo de } \\
\text { consorcio de } \\
\text { exportación }\end{array}$ \\
\hline $\begin{array}{l}\text { Joint } \\
\text { Venture }\end{array}$ & $\begin{array}{c}\text { Medio/ } \\
\text { Largo plazo }\end{array}$ & 20 más & Sí & Capital & $\begin{array}{l}\text { Horizontal } \\
\text { y vertical }\end{array}$ & Ilimitado & Sí & $\begin{array}{l}\text { Realización } \\
\text { proyectos } \\
\text { conjuntos }\end{array}$ \\
\hline $\begin{array}{l}\text { Consorcio } \\
\text { de } \\
\text { exportación }\end{array}$ & $\begin{array}{l}\text { Corto/ } \\
\text { medio } \\
\text { plazo }\end{array}$ & 20 más & Sí & Contractual & $\begin{array}{l}\text { Horizontal } \\
\text { y vertical }\end{array}$ & Limitado & Sí & $\begin{array}{l}\text { Desarrollo } \\
\text { de mercados } \\
\text { exteriores. }\end{array}$ \\
\hline $\begin{array}{l}\text { Consorcio } \\
\text { de } \\
\text { exportación } \\
\text { enfocado } \\
\text { (CEXEN) }\end{array}$ & $\begin{array}{c}\text { Corto/ } \\
\text { Medio y } \\
\text { Largo plazo }\end{array}$ & De 2 a 10 & Sí & Contractual & Horizontal & Ilimitado & Sí & $\begin{array}{c}\text { Diseñar y a } \\
\text { poner en } \\
\text { práctica una } \\
\text { estrategia } \\
\text { comercial de } \\
\text { exportación } \\
\text { común ( no } \\
\text { se limitan a } \\
\text { llevar a cabo } \\
\text { ciertas } \\
\text { acciones de } \\
\text { promoción) }\end{array}$ \\
\hline
\end{tabular}

\section{VENTAJAS EN SU FORMACIÓN}

Las ventajas o beneficios generados en formas asociativas $\mathrm{y}$, por ende, en la participación en consorcios de exportación son varios y no se lograrían alcanzar de manera individual. Entre ellos pueden destacarse los siguientes:

\subsection{Ingresos}

Dentro de un consorcio de exportación por definición la empresa es más competitiva, ya que tiene una mejor y mayor oferta -economías de alcance-, dada la suma o integración de todas las empresas y sus productos y/o servicios. Esta mayor oferta permite defender los clientes actuales (Buckley y Casson, 1988 y Martínez Carazo, 2003) y captar nuevos clientes 
(Barcenilla, 2013). Igualmente, es importante el efecto arrastre, ya que si alguno de los productos resulta especialmente atractivo para los clientes puede ayudar a las ventas de los demás productos y/o servicios. Otro aspecto a tener en cuenta es el que apunta (Martínez Carazo, 2003), ya que uno de los beneficios relacionados es la posibilidad de obtener subvenciones en programas de organismos públicos nacionales, regionales y locales. Cuando se es más competitivo, como conclusión genérica y plana se favorece sin duda el aumento de los ingresos (Burgers et al., 1993; Gomes-Casseres, 1994).

\subsection{Gastos y costes}

Al producirse economías de escala, por aumentos de producción, se amplía la eficiencia, lo que lleva a una reducción de los costes y gastos de la empresa (López Navarro, 2001). En definitiva, no sólo existen los beneficios directos e inmediatos de repartir gastos en la gestión comercial, logística o de marketing (Hennart, 1991; Martínez Carazo, 2003; Thorelli, 1986), sino que hay que añadir los correspondientes a las economías de escala (Contractor y Lorange, 1988 y Oliver, 1990) conseguidas y la eficiencia de los recursos aplicados al proyecto.

\subsection{Redes}

A pesar de ser un beneficio menos dado a conocer o valorado por la empresa este beneficio representa, sin embargo, un pilar de desarrollo a medio y largo plazo a tener en cuenta, además de representar un menor riesgo y perjuicio en casos de toma de decisiones entre inversiones alternativas (Barcenilla, 2013). Un consorcio de exportación puede ser también más eficiente dentro de un conglomerado desarrollado que en un medio aislado, como resultado del acceso más fácil a recursos y a instituciones de apoyo (ONUDI, 2004). Una ventaja que resulta fruto de las redes que se crean, donde el consorcio de exportación y la mentalidad de cooperación que se desarrolla y se genera en su interior, pueden en sí mismas constituir un primer paso hacia el mejoramiento de la colaboración entre empresas de una región determinada o servir de ímpetu para el desarrollo de un conglomerado.

Al emprender conjuntamente actividades en el marco del consorcio los miembros desarrollan lazos personales, comerciales y de confianza. No obstante, los consorcios de exportación (y las estructuras intermedias semejantes) no sólo desempeñan un papel clave para facilitar la cooperación entre empresas, sino además para mejorar los vínculos entre las empresas y las instituciones que las rodean. Así, los consorcios resultan fundamentales para que las empresas tengan confianza en su medio local y refuercen el rendimiento del conglomerado. Las redes que se crean y fortalecen entre empresas durante su participación en un consorcio pueden facilitar la colaboración entre empresas en esferas no relacionadas con las exportaciones, incluso con empresas que ya no sean miembros del consorcio (ONUDI, 2004). Por tanto, el beneficio del acceso a redes conlleva las siguientes ventajas: Facilitar y promover la cooperación que lleva a un mayor y mejor conocimiento (Meier, 2011); provoca más y mejores relaciones profesionales e institucionales (Galaskiewicz, 1985); ayuda a realizar una mejor elección de alternativas y a una mayor eficiencia en los nuevos proyectos (Oliver, 1990) y conlleva menores riesgos en las decisiones y asignación de recursos (ONUDI, 2004).

\subsection{Activos intangibles}

Martínez Carazo (2003) hace referencia al beneficio de los activos intangibles refiriéndose a las sinergias e intercambio de información, a la gestión profesionalizada, al 
poder de negociación, a la experiencia y aprendizaje. También se añaden activos intangibles como el know-how del grupo y de sus miembros, a sus activos estructurales, entendidos a sus culturas, procesos y estructuras, activos relacionales que disponen cada una de las empresas y a la propiedad intelectual (Meier, 2011). En definitiva, se habla de los activos intangibles y el enlace de éstos con un proyecto de cooperación empresarial. Estos han pasado a ser elemento de alto interés en los proyectos de cooperación, como elemento aglutinante, comunicador, motivador y enriquecedor de las empresas partners y su relación grupal (Barcenilla, 2013).

\section{FACTORES DETERMINANTES EN LA FORMACIÓN DE UN CONSORCIO}

A la hora de analizar los factores que influyen en la salida al extranjero como consorcio de exportación es preciso distinguir entre aquellos que responden a factores internos y aquellos que son de carácter externo a la empresa y que influyen de manera importante en la decisión de utilizar el consorcio como vía o apoyo al proceso exportador de las pymes:

- Factores externos: las políticas comerciales, inestabilidad política, distancia geocultural, competencia de empresas locales, mercado de productos y el desarrollo y crecimiento del país extranjero pueden producir lo que algunos autores denominan volatilidad o incertidumbre en el ambiente externo. Martínez Carazo (2003) confirmó que de los consorcios analizados en su estudio uno de los factores influyentes fue la distancia cultural que pudiera existir, destacando que fue uno de los objetivos cumplidos en dichos consorcios. Así, factores que motivaron a entrar en consorcio fueron países con distintos idiomas, culturas, gustos de los consumidores, formas de promoción de los productos, etc., y que pudieron ser salvadas por la gestión de los gerentes comerciales en las plataformas de venta.

- Factores internos: con relación a los factores intrínsecos de las empresas se encuentra la propia motivación a internacionalizarse, la reducción de los costes de promoción externa y el intercambio de experiencias. Igualmente, apuestan por la cooperación para reducir barreras para la internacionalización (Martínez Carazo, 2003). Algunas empresas no consideran como netamente importante para su proceso de internacionalización el estar vinculado a un consorcio de exportación, de ahí que el consorcio no siempre se crea sólo para exportar, sino para crear proyectos con múltiples propósitos. Para Lu y Beamish (2001) el establecimiento de alianzas o acuerdos estratégicos con otras empresas facilita la captación de nueva información, esencial para acometer con ciertas garantías y el menor riego posible la aventura de la internacionalización o nuevas aventuras en mercados por acometer. Fernández (2014), por su parte, destaca la diversificación de las exportaciones y penetración de regiones de difícil acceso. Este factor suele ser común en empresas que ya exportan y que, dentro de su plan estratégico internacional, se plantean la salida en consorcio de exportación para ir penetrando en mercados de difícil acceso o que requieran de muchos esfuerzos promocionales. Normalmente, estas empresas utilizan consorcios promocionales, ya que disponen de estructura y recursos para llevar por sí solos la etapa de comercialización, respetando sus marcas y sin entrar bajo la marca del consorcio.

Entre los principales factores internos que inciden en esta salida para la internacionalización, se encuentran las siguientes: Escasez de personal cualificado en exportación; ausencia de información sobre los mercados; falta de capital en inversiones para mejorar la calidad de los procesos productivos, de la promoción de ingresos en los mercados y de la capacitación; falta de volúmenes de producción para interesar a grandes compradores; carencia de marca propia; carencia de poder contractual con proveedores, clientes, bancos y entidades gubernamentales; y poco hábito de planeamiento estratégico. 


\section{PERVIVENCIA EN EL TIEMPO DE LOS CONSORCIOS DE EXPORTACIÓN}

Una de las grandes cuestiones de interés sobre los consorcios de exportación es su pervivencia a lo largo del tiempo. Se identifica una clara carencia de estudios de investigación de rigor y que respondan a análisis empíricos que se hayan centrado en este aspecto, por lo que puede ser objeto de futuras líneas de investigación.

Uno de los autores que trata este aspecto con una mayor profundidad es Renart (2002). El autor delimita la vida del consorcio a través de una serie de etapas: definición, incertidumbre, consolidación y desarrollo. Para ello, diseñó un gráfico donde mezcla dos variables: el tiempo, donde se analiza desde el momento previo de contacto de empresas y promotor de consorcio hasta que cesa su actividad; y la motivación de pertenencia a través de lo que llama como nivel de motivación total (MPT) para permanecer en el consorcio demostrado por las distintas empresas-socio durante las diferentes etapas de su desarrollo. Mediante el mismo indica que los valores de la MTP se incrementan cuando se inicia la etapa de definición; luego, marca la etapa de incertidumbre donde los valores de la MPT se estancan ya que es un momento delicado para su formación. Una vez superada la etapa de incertidumbre, marca la etapa de consolidación donde los valores de la MTP aumentan, a partir de ese momento o se llega a la disolución o si está diseñado y gestionado correctamente alcanzará unos valores máximos durante la etapa de desarrollo.

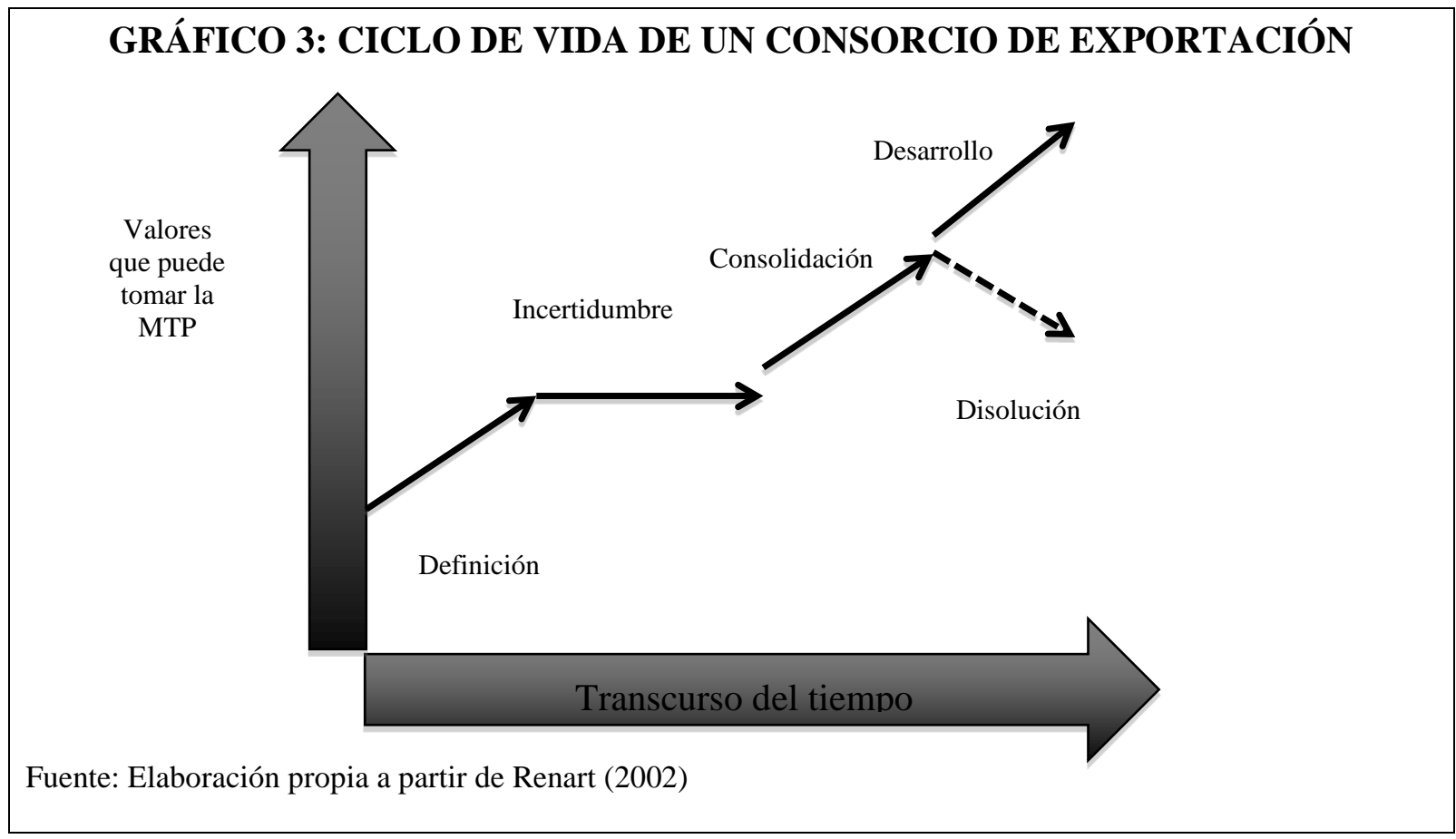

Renart (2002) llegó a delimitar en sus trabajos un horizonte temporal para la fase de gestación del consorcio aproximado de entre seis meses y dos años (fase definición e incertidumbre), señalando la dificultad de esta fase ya que observa que un alto número de consorcios que se intentan formar no consiguen llegar al momento de constitución formal. Por otro lado, y teniendo en cuenta que la mayoría de estas iniciativas son impulsadas por subvenciones de organismos de promoción exterior, se ha revisado las condiciones de estas 
ayudas, limitando el periodo de gestación a 6 meses en los programas promovidos por el Instituto de Comercio Exterior (ICEX).

La duración de los consorcios de exportación vienen limitadas en muchos casos por las propias subvenciones de los programas que lo promueven. Así se encuentra un periodo estándar de 4 años de duración de los consorcios de exportación en programas como el de ICEX, EXTENDA o IGAPE. Lo importante también es analizar cuántos consorcios siguen vigentes tras ese periodo marcado por el programa. Puestos a revisar estudios que se hayan centrado en ese análisis, se hace referencia a Castro y Moneu (1993), en el que estudió 95 consorcios creados por ICEX por subvención en el periodo de 1985-1992, de ellos el 58 por 100 seguían activos un año después. También se encuentra el único informe del ICEX sobre análisis de duración del consorcio que crearon "Informe sobre los consorcio de exportación en España" que data del año 1996. En el mismo se apunta que del periodo de 1985-1996, al año siguiente a su finalización estaban funcionando el 80 por 100. Más recientemente ICEX (2007) analiza periodos de 1985 a 2001 y donde se amplia el seguimiento a 2007, es decir, seis años posterior a la fecha de finalización. En el mismo, se apuntaba que seguían activos 90 de los 330 consorcios creados hasta la fecha, es decir un 27 por 100 de los mismos. Lo que sí parece determinante en la pervivencia del consorcio es el apoyo de administraciones públicas o de iniciativas público-privadas.

Es importante en este punto resaltar que no siempre se va a considerar como un fracaso la finalización del consorcio, ya que muchos de ellos tienen como finalidad ser proceso transitorio de empresas y rampa de lanzamiento, bien de su proceso de exportación o de la entrada en un mercado en concreto, así lo apuntaba una funcionaria de la Cámara de Comercio de Sabadell entrevistada por Rialp et al. (2005). Se busca en muchos casos una duración limitada para beneficiarse de bases comerciales y de conocimientos para luego seguir su aventura de manera individual. Es por eso que es conveniente también en este tipo de estudios realizar análisis de las ventas de esas empresas de manera particular en esos mercados tras la finalización del consorcio.

En este sentido ICEX (2007) afirma que en tanto que sea una escuela de aprendizaje será un instrumento transitorio y condenado a disolverse en 3-5 años, tan pronto como los socios sean capaces de exportar de forma independiente. Como instrumento destinado a lograr objetivos ambiciosos, un consorcio con una correcta gestación al principio y bien dirigido, puede tener una duración indefinida. Así, se apunta que tras el consorcio es cuando en ocasiones aparecen nuevas oportunidades en los mercados y el consorcio puede encontrar otras vías de negocios. Renart (2002), avisando de los pocos datos y estudios rigurosos y científicos que se disponen y basándose de las observaciones puntuales que ha llevado a cabo, afirma la hipótesis de que los consorcios de exportación en España suelen tener una duración limitada en el tiempo. Además, se atreve a proponer que en España los consorcios de exportación puedan tener un ciclo de vida de entre unos 6 años $(2$ de gestación y 4 de funcionamiento) y unos 10 años.

\section{TIPOS DE CONSORCIOS}

\subsection{Según tipo de actividad}

Los consorcios de exportación pueden ser creados para distintos objetivos. A veces, de hecho son creados para un determinado fin y con un propósito claro incluso en mercados determinados. Así, se identifican los siguientes: 


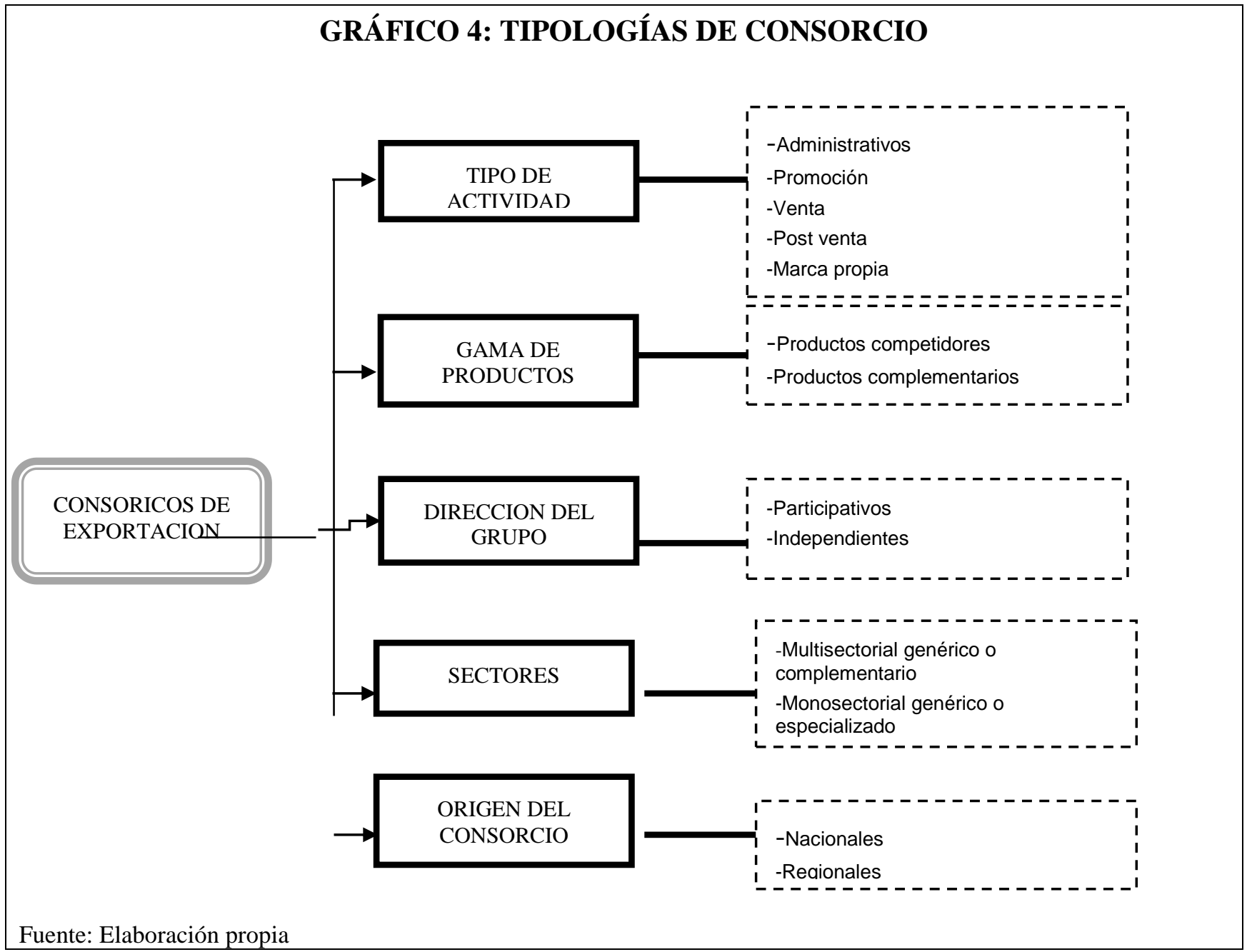

- Con funciones básicas administrativas: Hay algunos que ofrecen sólo funciones básicas de secretaría, tales como proporcionar información, organizar programas de capacitación, ayudar con traducciones y/o hacer investigación de mercado. No obstante, los hay también que ayudan a los miembros a formular un Plan Estratégico Internacional con una estrategia completa de exportación y prestan una mayor diversidad de servicios, incluidas adquisiciones colectivas de insumos, asistencia jurídica, la creación de una marca del consorcio y otras formas de comercialización.

- Consorcios de exportación de promoción: Errecart (2013) y ONUDI (2004) hacen especial hincapié, de igual forma que la mayoría de autores en la distinción entre los de promoción y los de venta, los dos tipos de consorcios de exportación más utilizados. Estos consorcios de promoción tienen como principal objetivo adentrarse en mercados compartiendo los costes de las acciones de promoción y logísticos. Asisten a ferias, misiones comerciales directas e inversas, showroom, catas de producto, demostraciones, encuentros de negocios, agendas individuales, acciones en punto de venta y compra, y cualquier otro tipo de acción promocional, actuando bajo el nombre del consorcio y exponiendo todos los productos y/o servicios que aglutinan. Estos consorcios se limitan a realizar este tipo de actividades, siendo las empresas las que realizan individualmente las ventas y sus gestiones

El principal objetivo es la promoción internacional conjunta de los productos de las empresas que lo integran. Las negociaciones y exportaciones las realiza cada empresa independientemente, quedando labores exclusivamente promocionales. Este consorcio se crea 
habitualmente por un contrato, lo que no suele llevar a una nueva forma jurídica. Para Errecart (2013), los consorcios de promoción tienen las siguientes características: el objetivo es promover los productos que ofrecen sus miembros; comparten costos de logística y promoción; apoyan y asisten para facilitar el acceso a ciertos mercados; las ventas las realizan directamente las empresas; y el número de miembros no es alto.

- Consorcio de exportación de venta: constituyen una entidad que canaliza las exportaciones de los miembros. Asimismo, realizan actividades de promoción comercial y llevan la gestión comercial y de venta de los productos de las empresas participantes. Para velar por una imagen determinada, esos tipos de consorcios suelen controlar la calidad de los productos comercializados. El principal objetivo es la venta internacional conjunta de los productos de las empresas que lo integran. Normalmente, se constituye una nueva empresa (consorcio de exportación de venta con contabilidad independiente). Las promociones, negociaciones y exportaciones las realiza esa nueva empresa, que suele ser gestionada por un gerente de exportación.

Errecart (2013) añade las siguientes características a este tipo de consorcio: Realizan promoción comercial y organizacional; organizan la venta de los productos de los miembros; la mayoría promueve la venta del producto a través del consorcio, no por la empresa; controlan la calidad de los productos ofrecidos para garantizar la imagen del consorcio; el número de empresas es limitado y las empresas delegan la autoridad para hacer negocios en su nombre al gerente del consorcio.

Existen dos tipos de consorcios de venta (ONUDI, 2004): a) consorcios de comercio, es decir, los que adquieren los productos de las empresas participantes con el fin de revenderlos, y b) consorcios que actúan como agentes de exportación. Renart (1997) añade que mientras en los primeros el consorcio negocia créditos y paga a las empresas participantes por sus productos, en los segundos las empresas participantes envían sus propios recibos y tratan de obtener el pago de sus clientes.

Aunque puede variar según el consorcio y sus normas, la mayoría de los consorcios de venta no permiten que las empresas participantes exporten por su cuenta y les exigen que utilicen al consorcio en su lugar. Algunos consorcios de venta aplican esta norma a todos los productos y/o servicios y países, otros se limitan a los mercados que constituyen su objetivo y a los productos que se venden por acuerdo del consorcio (Welch y Joynt, 1987).

- Consorcio de exportación de postventa: Estos tipos de consorcios son muy importantes y habituales para los productos industriales que requieren un servicio de asistencia técnica posterior a la venta en destino y un mantenimiento de ese contacto con el cliente. Hoy en día se requiere de presencia en los mercados y este consorcio ayuda a dar esa asistencia en el mercado de destino. Las empresas se agrupan para compartir este servicio.

- Consorcio de exportación con marca propia: A la hora de crear un consorcio se puede decidir realizar una marca que aglutine a todas las empresas y con las que vender en mercados extranjeros. Esto constituye una delegación de poder por parte de las empresas, ya que pierden el control sobre el posicionamiento de su marca en el mercado internacional en beneficio de mayores ganancias comerciales (Fernández, 2014). Por ello, las empresas que van buscando posicionamiento en el mercado apostando por la marca no les interesa este tipo de consorcio. Cuando no se quiere delegar esa competencia de la marca propia, se opta por consorcios en los que se mantenga la marca de cada una de las empresas. 


\subsection{Según la gama de productos que ofrece}

- Consorcios de exportación de productos competidores: Es la unión de empresas que exportan productos y/o servicios similares con la finalidad de ofrecer al mercado mayores volúmenes de estos productos como consorcio de exportación. Este tipo de consorcio de exportación es útil cuando los clientes requieran de mayor cantidad que una sola empresa puede ofrecer.

- Consorcios de exportación de productos complementarios: Unión de empresas que exportan productos y/o servicios complementarios con la finalidad de ofrecer al mercado una gama amplia. Este tipo de consorcio es utilizado para dar servicios integrales o de llave en mano, tendencias que están actualmente al día y es demandado en los mercados exteriores.

\subsection{Según la dirección del grupo}

Tomando como referencia el trabajo de Provan (1984) se distingue los siguientes consorcios en función de la dirección del grupo:

- Consorcios participativos: En este tipo de consorcio los socios interactúan entre sí para tratar cuestiones estratégicas y coordinar su organización y relaciones entre sí, por lo que se puede decir que juegan un papel activo en la dirección del grupo.

- Consorcios independientes: A diferencia de los participativos, no existe una interdependencia entre los socios como tal, ya que es coordinada por un staff de miembros. Se encargan, por tanto, de tareas tanto operativas y estratégicas, teniendo cierta independencia.

Dada la mayor importancia que las empresas atribuyen a las actividades de venta, frente a las de soporte o las promocionales, parece más probable que los consorcios que desarrollen dicha actividad tengan un carácter más participativo. Como resultado del incremento de complejidad que resulta de la mayor interacción entre los socios, fruto de su papel activo en la dirección del grupo, las estructuras participativas suelen tener un menor número de afiliados que las independientes. Ello conlleva que el número de empresas que conforman consorcios para el desarrollo de actividades de venta sea menor, frente al resto de modalidades consorciales cuyo carácter, a raíz de lo expuesto anteriormente, es más independiente.

\subsection{Según sectores}

Respecto a la localización de las actividades del grupo, Lanzara, Varaldo y Zagnoli (1991), clasificaban a los consorcios hasta en cuatro distintos tipos (multisectorial -genérico o complementario- y monosectorial-genérico o especializado-). Es de destacar que estos autores sólo hacen referencia a productos, sin tener en cuenta a las empresas de servicios que también forman parte de consorcios de exportación, aunque los de productos sean los más usuales.

- Multisectorial genérico o complementario: Hace referencia a empresas que no son del mismo sector, pudiendo mezclarse distintos tipos de sectores con productos y/o servicios relacionados o no relacionados. Se diferencian ya que el genérico trata de productos que difícilmente pueden integrarse en una misma estrategia exportadora y, por tanto, la labor del consorcio suele consistir en el desempeño de actividades de soporte de carácter básico. Por el contrario, en el complementario ofrecen conjuntamente algún tipo de producto y/o servicio final al cliente, o bien, coordinan la comercialización de líneas de productos distintas pero interrelacionadas. Suele tratarse en los consorcios complementarios de consorcios de venta. 
La principal ventaja de los consorcios multisectoriales es que pueden ofrecer una mayor variedad de productos. Igualmente, se hace referencia a que suelen ser empresas radicadas en una misma zona geográfica. Pese a la diversidad de empresas en un consorcio multisectorial, el grupo ha de estar en condiciones de presentar una imagen común (Errecart, 2013). Por ello, es esencial que los productos de los miembros sean compatibles en lo que se refiere a diseño y calidad. Igualmente, es importante, a veces, que los canales de distribución que se toquen sean los mismos o el posicionamiento en el mercado de la marca sea parecido.

- Monosectorial genérico o especializado (horizontales y verticales): Formado por empresas del mismo sector de actividad y que fabrican y producen los mismos productos y/o servicios. Los genéricos no suelen ser habituales debido a que no se quiere entrar con la competencia a vender en mercados internacionales, centrándose en esos casos en consorcios promocionales o para funciones de venta. Las actividades que desarrollan, además de los servicios de soporte básicos como en los multisectoriales genéricos, se extienden a servicios tales como información de carácter técnico o actividades de promoción comercial. Cuando los consorcios están compuestos por competidores directos, se va buscando generar economías de escala ya que están orientados a esos bienes o servicios. Sí es cierto, que en este caso son más comunes en productos para generar esas economías de escala y no tanto en servicios. En este último caso se dan para complementar partes específicas de ese servicio que la empresa subcontrate y que pueda ser dada por la competencia. Renart (1999) añade que en este tipo de consorcios entre competidores hay más oportunidades de compartir proyectos de I+D+i. Por otro lado, en el especializado, son empresas que fabrican productos y/o servicios distintos y complementarios. De igual forma que en el caso de los multisectoriales, suelen tratarse de consorcios orientados a la venta.

Otra forma de denominar a este tipo de consorcios es de carácter horizontal o vertical, en función de si ofrecen los mismos productos y/o servicios o son de carácter complementarios. Cuando la integración es horizontal, probablemente se identifique una potencial demanda exterior que una sola empresa no puede cubrir. Cuando la integración es vertical, las empresas se agruparán para conformar una oferta completa e integrada (Cabeza y Martínez, 2004).

\subsection{Según origen del consorcio}

Los consorcios también pueden ser clasificados en función de si son originarios de una determinada región, de diversas regiones o nacionales. Estos consorcios regionales o de varias regiones Errecart (2013) los relaciona directamente con si la iniciativa de establecer un consorcio procede de una cámara de comercio local, de una organizacional regional o de una organización nacional de empresas.

- Los consorcios nacionales: Este tipo de consorcios son integrados por empresas de distintas regiones y tienen la ventaja de que pueden poner en contacto a empresas dispersas desde el punto de vista geográfico, pudiendo mezclarse distintos productos con variedades distintas - por ejemplo, aceite de oliva o vino- y conformar una oferta variada de una nación. De esta manera son más representativos y pueden dar como resultado menos competencia entre miembros que los grupos regionales.

- Los consorcios regionales: Estos, que como se ha dicho anteriormente suelen ser desarrollados por organismos regionales o locales, suelen tener un objetivo local concreto por ejemplo, la promoción de productos alimentarios típicos o de artesanías-. Se suele dar en poblaciones no muy grandes donde los esfuerzos de organismos públicos y/o privados hacen aglutinar a las empresas para salir en ocasiones bajo la marca de la zona. Ese tipo de consorcios suele surgir de distritos industriales, conglomerados o clusters. Dentro de esos 
conglomerados se facilita la cooperación entre las empresas. Normalmente, son formados con empresas con escasa capacidad de producción o de reducidas dimensiones, aspecto que suele ser contrarrestado por la unión de las mismas y por su facilidad de acceder a proveedores de repuestos y servicios, de igual forma que a subcontratistas. Son consorcios donde se crean riqueza en una población y se da la exportación por arrastre, al beneficiarse otras empresas indirectamente. La ventaja competitiva de las PYME agrupadas en conglomerados se basa en tres aspectos interrelacionados: especialización, cooperación y flexibilidad (ONUDI, 2004).

\section{FACTORES DE ÉXITO Y PUNTOS CRÍTICOS}

\section{Actitudes directivas:}

- Las actitudes directivas de los propietarios, gerentes de las empresas que lo constituyen y del gerente del consorcio son un factor clave para el funcionamiento de un consorcio. Para ello en algunos consorcios se exige que la empresa ya esté exportando de manera consolidada o se encuentre internacionalizada, ya que habrá más probabilidad de que existan gerentes con actitudes ya adaptadas y abiertas a la internacionalización (Renart, 1999).

- Es igualmente importante detectar en los gerentes de las empresas valores éticos y morales que facilitan el trabajo en equipo, la toma de decisiones, el diseño de los estatutos que rigen las actuaciones de los miembros del grupo, el diseño de objetivos comunes, el intercambio de recursos y capacidades, la ayuda mutua, y otros elementos presentes en las relaciones de empresas y personas (Martínez Carazo, 2003).

- El estudio de Lim, Sharkey y Kim (1991) profundiza en este aspecto resaltando cuatro aspectos importantes en estas actitudes directivas: conciencia, interés, intención y adopción. En el primero de ellos, los directores de las empresas y del consorcio toman conciencia de la importancia de la exportación como salida estratégica para la empresa, para su supervivencia y/o desarrollo; con respecto al interés, se muestran dispuestos a la exportación de sus empresas y tienen una disposición favorable; en tercer lugar, ese interés que muestran les lleva a tener una clara intención hacia la exportación que les lleva a la acción; y, por último, adoptan la exportación como una nueva actividad de las empresas utilizando para ello el consorcio de exportación. Cuatro variables que son dispuestas en un orden secuencial y que si de inicio se incluyen empresas que ya exportan o están internacionalizadas hace el periodo más corto de asimilación.

Fase de internacionalización de la empresas participantes

- Con relación a la fase de internacionalización más adecuada en la que deben encontrarse las empresas, como ya se adelantó anteriormente se recomienda que las empresas participantes en el consorcio de exportación, tengan ya experiencias internacionales (López Navarro y Camisón, 1999; Barcenillas, 2013). Así, se asegura que las empresas que entren al mismo hayan tenido experiencias previas en exportación, bien sea vía indirecta o directa, que asegura conocer la exportación, las dificultades, riesgos que conlleva. Los consorcios de exportación no sirven para que las empresas aprendan a exportar. Con esto se gana en que ya conocen los retos, riesgos, ventajas y desventajas que ello supone, para agilizar y optimizar la toma de decisiones en el seno del consorcio de exportación. Además es aconsejable que las empresas cuenten ya con oferta exportable. 
- Los consorcios de exportación no constituyen una buena solución para las empresas que pasan a abordar esta primera etapa -de exportación experimental(López Navarro, 1999), ya que su carácter exploratorio dificulta que comprometan recursos en la actividad colectiva, a la vez que reduce su disponibilidad para coordinar los esfuerzos del grupo, lo que sin duda reduce la efectividad del conjunto (D'Aunno y Zuckerman, 1987).

En esta idea, López Navarro (2014) cuestiona aquellos proyectos en los que los socios, muchas veces, sin experiencia en el plano exportador, constituyen un consorcio de exportación con el deseo de iniciar un periodo de prueba en el contexto internacional con un coste relativamente bajo, pero con el objetivo, muchas veces no revelado, de abandonar la relación en un plazo relativamente corto para continuar la aventura internacional en solitario.

Por tanto, se aconseja que el consorcio de exportación sea una solución para empresas que se encuentren en primeras fases de exportación entre la ocasional o experimental como apuntaba Camisón y López Navarro (1999), intentando alcanzar las exportaciones activas que sería el siguiente nivel de internacionalización. Ese paso, donde ya la empresa ha comenzado a tener pequeñas experiencias en exportación y va buscando una estructura y mayores requerimientos, es donde las empresas necesitan más ayuda y la asociación se torna importante (Bamberger y Evers, 1994).

\section{Perfil empresas participantes}

La importancia de este punto radica en poder ayudar a identificar correctamente las empresas que van a formar el consorcio de exportación. El éxito del consorcio, vendrá motivado por una correcta definición de las empresas que cumplan el perfil adecuado para formar esta fórmula asociativa. Así, se recogen y elaboran las siguientes recomendaciones:

- Es importante detectar empresas donde exista una cultura organizacional que tenga, entre otras, estas características:

$\checkmark$ La flexibilidad y rapidez en la toma de decisiones, que caracterizan a estas empresas, pueden afectar positivamente a la formación de alianzas (Gallo et al., 2002).

$\checkmark$ Compatibilidad en la cultura organizacional (López Navarro, 2001).

$\checkmark \mathrm{Su}$ orientación a largo plazo que llevan en las empresas a mayores niveles de compromiso y confianza que muestran (Vallejo, 2008), caracterizadas por su fiabilidad y estabilidad y por asumir con facilidad compromisos relacionados con su orientación a largo plazo (Hovi, 1994; Kets de Vries, 1993). En este sentido López Navarro (2014) incide que la orientación a largo plazo de los socios resulta determinante en su compromiso, esto es, en la determinación de los recursos y esfuerzos que están dispuestos a dedicar para facilitar el desempeño de la relación consorcial.

$\checkmark$ Orientada al trabajo en equipo, la colaboración interna como clave.

$\checkmark$ El intercambio de los recursos y capacidades, en este sentido la convergencia de estos entre los miembros se considera clave para la transferencia de activos y recursos, así como lo que un miembro transfiere y lo que otro puede asumir y gestionar (Barcenillas, 2013 y Duysters y Lokshin, 2011).

$\checkmark$ El conjunto de fortalezas que caracterizan a la empresa familiar (Hovi, 1994; Kets de Vries, 1996; Poutziouris, 2001) presentan aspectos muy ventajosos para la formación de estos consorcios de exportación. 
- Uno de los aspectos importantes sobre las empresas que van a participar en un consorcio de exportación es que cuenten ya con experiencias internacionales, con exportaciones ya realizadas, consolidadas o incluso en fases avanzadas de internacionalización.

- Se considera que la similitud y convergencia entre empresas miembro de un proyecto de cooperación tienen un efecto positivo en los resultados de la misma (Kim y Parkhe, 2009). Es por ello que se cree clave una buena selección y diseño de los consorcios de exportación.

- Martínez Carazo (2003) aconsejaba empresas que formen consorcios complementarios, evitando la competencia interna y configurando una amplia gama de productos/servicios que proporcionen servicios integrales, o que satisfagan necesidades, gustos o exigencias de los consumidores.

- Otro de los aspectos, va relacionado con los criterios que suelen demandar a la hora de solicitar subvenciones públicas (Rialp et al., 2005). Uno de los grandes apoyos que se han realizado desde las administraciones públicas ha sido las subvenciones a la creación de consorcios de exportación tanto por parte de administraciones nacionales como autonómicas. Para ello, es necesario que las empresas posean 100 por 100 de capital español.

\section{Gerente de consorcio}

- Se identifica como una figura clave especialmente cuando se constituye por empresas de reducida dimensión, que puedan presentar lagunas en los que concierne a la planificación estratégica en experiencia exportadora (López Navarro, 2001).

- El gerente debe tener los conocimientos, experiencia, educación específica en comercio exterior. Se debe seleccionar gerentes que sean expertos en comercialización y, si pudiera ser, en actividades de formación de grupos de cooperación empresarial. Debería tener un conocimiento amplio y experiencia del sector en que operan los miembros, así como contactos personales con diversas posibles empresas participantes y organismos relacionados con el sector y la exportación tanto nacionales, como internacionales.

- Por otro lado, y más allá de sus dotes profesionales y experiencias, el gerente debe mostrar unas capacidades y habilidades especiales tales como capacidad de liderazgo, personalidad y motivación. La elevada calidad motivacional del gerente posiblemente sea uno de los factores que contribuye de manera importante, quizás decisiva, al éxito o fracaso del consorcio (Renart, 1999). Además, debería ser capaz de motivar a los futuros miembros y tener aptitudes para zanjar controversias y negociar, así como la flexibilidad y voluntad necesarias para ayudar a los futuros miembros a encontrar una solución aceptable para todos (ONUDI, 2004). Los gerentes que son líderes, fuertes y motivadores promueven las aportaciones y participación de todos pueden incrementar las manifestaciones de opiniones del resto de miembros del grupo, debido al menor temor al riesgo de hablar en grupo (Gao, Janssen y Shi, 2011; Premeaux y Bedeian, 2003).

\section{Nivel de compromiso}

Varios autores señalan el compromiso de las empresas como contribución de manera directa a mejorar los acuerdos de cooperación y de ayudar a eliminar los comportamientos oportunistas e individuales, favoreciendo, por tanto, el correcto desarrollo de los objetivos y beneficios de una cooperación empresarial (Morgan y Hunt, 1994; Skarmeas et al., 2002; 
López Navarro, 2001; Karsikeas y Schelegelmich, 2002; Pesämaa y Hair, 2007; y Nakos y Brouthers, 2008). Igualmente, se cree relevante el compromiso de los socios en un momento importante como es la puesta en marcha del acuerdo y en su desarrollo (UNIDO, 2009; Ghauri et al., 2003).

López Navarro (2001) añade además que la falta de vocación y de capacidad exportadora de alguno de los socios, cuyo objetivo para integrarse en un consorcio reside en la posibilidad de adentrarse en mercados internacionales con un coste mínimo y aprovechando las subvenciones, constituye uno de los principales problemas en muchos consorcios de exportación una vez constituidos. Dando continuación a esa línea el mismo López Navarro (2014) realizó un estudio que se centró en el nivel de compromiso de las empresas para el éxito en un consorcio, un nivel de compromiso que relacionaba con el interés estratégico que tenían las empresas a la hora de pertenecer a un consorcio de exportación, es decir, un interés a largo plazo. En este sentido, el sentimiento de pertenencia a corto plazo, estaba relacionado con el sentimiento oportunista, socavando desde el inicio las bases necesarias para posibilitar su adecuado desarrollo, ya que se inhibe a la hora de exponer recursos y esfuerzos en favor de la actividad objeto de colaboración.

\section{Nivel de confianza}

Uno de los aspectos en los que se hace referencia para el éxito en un consorcio de exportación, y en definitiva, en la cooperación empresarial es el nivel de confianza existente entre las empresas. Se considera esencial para el eficaz desarrollo y eficiente resultado de cooperación (Barcenillas, 2013 y Fulmer y Gelfand, 2012). La confianza es definida por Morgan y Hunt (1994), resaltando la percepción de fiabilidad y habilidad para predecir el comportamiento de la otra parte en la relación, así como la seguridad de que los demás participantes no actuarán de manera oportunista ni aprovechada.

La confianza ha sido desarrollada por varios autores que serán citados a continuación centrándose en una doble vía: confianza en el gerente y la confianza entre los miembros participantes.

- La confianza de un grupo en el gerente, debe de partir de la percepción del mismo como un líder. El considerarlo como un líder ayuda a aumentar la solidez del grupo, incluso ante situaciones desfavorables (Brockner et al., 1997), incrementa la credibilidad de la información que aporta y el compromiso con las decisiones que toma (Dirks y Ferrin, 2002). El mismo autor considera un soporte positivo para el compromiso con el grupo y un elemento disuasorio ante la intención de abandonar.

Barcenillas (2013) que continúa en esta línea, añade que además del gerente, esa figura de líder puede ser tomada por una empresa que representa una clave de confianza y seguridad insustituible para el lanzamiento de un proyecto de cooperación y para la ejecución del plan establecido. Además, ambas figuras son esenciales cuando se retrasan los resultados, o cuando estos son desiguales entre miembros.

- Con relación a la confianza interpersonal de los miembros, origina y crea un ambiente donde hay espacio para la creatividad de tanto quien confía, como de quien genera la confianza (Madjar y Ortiz-Walters, 2008; Moran, 2005). También se favorece un clima de motivación entre los participantes así como de los trabajadores implicados en el consorcio, si los hubiera, que facilita la gestión de calidad total en el trabajo, que incluye trabajo en equipo y mejora continua (CoyleShapiro y Morrow, 2003).

En este sentido, un estudio de Lapidot et al. (2007) relacionaba el nivel de confianza con la vulnerabilidad de los miembros. Cuando las empresas se sienten más vulnerables crean 
mayores niveles de confianza. Por último, esta buena relación y creación de confianza entre miembros de un grupo puede facilitar cooperaciones futuras (Rosanas, 2008).

Definición plan estratégico

- Todo consorcio de exportación debe diseñar un plan estratégico consensuado por todos los participantes donde aparezcan los objetivos estratégicos, objetivos específicos a corto plazo, acciones concretas vinculados a esos objetivos, recursos que se emplean, cronograma, presupuesto y nivel de ejecución.

- Igualmente, se deben contar con herramientas de evaluación y seguimiento para poder tomar decisiones adecuadas, corregir desviaciones y tomar medidas tanto preventivas como de corrección. Estas herramientas deben contar con tanto indicadores cuantitativos como cualitativos.

\begin{tabular}{|c|c|}
\hline \multicolumn{2}{|c|}{$\begin{array}{l}\text { CUADRO 2: RESUMEN DE LOS FACTORES DE ÉXITO Y PUNTOS CRÍTICOS } \\
\text { EN LOS CONSORCIOS DE EXPORTACIÓN }\end{array}$} \\
\hline FACTORES DE ÉXITO & PUNTOS CRÍTICOS \\
\hline $\begin{array}{l}\text { Expe } \\
\text { empr }\end{array}$ & npresa \\
\hline $\begin{array}{l}\text { Empresas que han exportado, están en fases } \\
\text { iniciales de exportación o en fases más } \\
\text { avanzadas }\end{array}$ & Empresas sin experiencia en exp \\
\hline $\begin{array}{l}\text { Empresas con compatibilidad de cultura } \\
\text { organizacional con el proceso de exportación y } \\
\text { demás empresas }\end{array}$ & al \\
\hline n complementarias entre sí. & petritrc \\
\hline listintas fases de toda la & $\begin{array}{l}\text { Empresas existentes en conso } \\
\text { la cadena de valor, o emp } \\
\text { actividades. }\end{array}$ \\
\hline Empresas consolidadas en mercado doméstico. & Empresas con probien \\
\hline $\begin{array}{l}\text { Gerente de consorcio externo, con perfil y } \\
\text { experiencia como director de exportación y con } \\
\text { capacidades y habilidades de liderazgo, } \\
\text { motivación y personalidad }\end{array}$ & $\begin{array}{l}\text { Gerentes perteneciente a alguna de las empresas } \\
\text { miembro, perfil comercial y sin habilidades para llevar } \\
\text { un grupo. }\end{array}$ \\
\hline $\begin{array}{l}\text { compromiso de las empresas en el } \\
\text { del consorcio alto }\end{array}$ & $\begin{array}{l}\text { Niveles bajos de compromiso en el consorcio de } \\
\text { exportación. }\end{array}$ \\
\hline $\begin{array}{l}\text { Adecuados niveles de confianza entre empresas, } \\
\text { y generación de un ambiente de confianza }\end{array}$ & $\begin{array}{l}\text { confianza entre empresas, y no exis } \\
\text { do. }\end{array}$ \\
\hline & $\begin{array}{l}\text { Carencia de un Plan Estratégico Internacional o no } \\
\text { consensuado y aprobado por todas las empresas. }\end{array}$ \\
\hline
\end{tabular}

Fuente: Elaboración propia

\section{CONCLUSIONES}

Como se ha puesto de manifiesto en este trabajo, las empresas suelen decidir salir fuera de forma agrupada debido principalmente a la falta de estructuras y recursos. Sin embargo, no todas las empresas que utilizan esta vía poseen exclusivamente motivos internos, sino que también obedecen a factores externos a las empresas. Igualmente, las empresas que ya exportan o que tienen una estructura adecuada y recursos para exportar, también a veces 
utilizan la salida consorciada, respondiendo, por tanto, a factores distintos a los de las empresas sin recursos.

Son múltiples las ventajas que presenta el consorcio de exportación para las pymes, pero hay que realizar una adecuada definición y preparación del mismo anteriormente para que no sea un fracaso su creación.

Igualmente, se aconseja realizar una correcta selección de las empresas participantes, donde se seleccionen empresas que se encuentren ya exportando o en fases avanzadas, ya que la constitución de consorcios por parte de empresas que no tengan ninguna experiencia en el ámbito internacional puede resultar contraproducente, debido a que a la dificultad de abrir mercados exteriores se une la complejidad que supone la gestión de una relación cooperativa.

Esas empresas también es importante que además de tener la experiencia de exportación, para crear unas adecuadas sinergias en el consorcio y perdure en el tiempo, representen las diferentes actividades de la cadena de valor. Esto ayuda a la mejora de los conocimientos y experiencias de las empresas, mejorando en innovación, procesos y tecnología lo que ayuda a las empresas a aprovecharse de sinergias. Por ello, es necesario identificar empresas que posean gama de productos y/o servicios amplios y profundos, lo que ayuda a la diversidad de su oferta y de la respuesta a todo tipo de necesidades y gustos en mercado de destino.

De igual manera, el perfil adecuado para formar parte de un consorcio de exportación es el de empresas que sean competitivas a nivel local y maduras en mercado doméstico con buenos posicionamientos. Este tipo de empresas normalmente no identifican la salida a la exportación como una necesidad urgente para su supervivencia corto plazo y, por tanto, no existan tensiones ni premura en conseguir resultados.

Identificar empresas que se les identifique un compromiso en el proyecto de consorcio será clave también de éxito, ya que un socio comprometido dedicará el tiempo y los recursos necesarios para lograr los objetivos de la relación de cooperación, lo que a su vez reduce la incertidumbre acerca de posibles comportamientos oportunistas en el futuro que pudieran redundar en el fracaso de la relación. De igual forma que el compromiso, será importante generar un alto nivel de confianza entre los miembros, lo que favorecerá el eficaz y eficiente resultado de cooperación.

Tan importante es identificar a las empresas correctas como seleccionar a un adecuado gerente de consorcio, clave en la formación y desarrollo de los consorcios. Este gerente debe reunir un perfil que corresponda más a un director de exportación que a un agente comercial, ya que tendrá un importante peso de labores de diseño y desarrollo de estrategia internacional del grupo, complementando su perfil con habilidades y capacidades como el liderazgo, personalidad y motivación para crear unidad, compromiso y confianza en el consorcio.

Por último, todo consorcio debe tener un plan estratégico internacional consensuado por todas las partes, que fije las bases estratégicas de su salida al exterior. Ese plan estratégico debe recoger los objetivos, acciones concretas en los mercados objetivo delimitadas con un cronograma y presupuesto, y las medidas de evaluación y seguimiento adecuadas para la supervisión de su ejecución y cumplimiento.

Todos estos puntos que aquí se recogen deben tomarse en cuenta en las futuras creaciones de consorcios de exportación, en la mayoría de los casos promovidos por administraciones públicas, que deben hacer especial hincapié en su proceso de creación y viabilidad del mismo, antes de su creación para evitar fracasos innecesarios a pymes donde se destinan un gran cantidad de esfuerzos tanto económicos como de tiempo. 


\section{BIBLIOGRAFÍA}

Bamberger, I. y Evers, M. (1994): "Internationalization Behaviour of Small and Medium Sized Enterprises- Empirical Results», en I. BAMBERGER (ed.): Product-Market Strategies of Small and Medium-Sized Enterprises, Aldershot, Avebury Ashgate Publishing, pp. 310-363.

Barcenillas, M.A. (2013): "La construcción de un proyecto de cooperación empresarial para la exportación”, Máster investigación en gestión de recursos humanos, trabajo y organizaciones, Departamento de Estudios económicos y financieros, y en el de psicología de la Salud, Universidad "Miguel Hernández" Elche.

Berg, S. V., Duncan, J. L. Jr. y Friedman, P. (1982): Joint venture strategies and corporate innovation, Cambridge MA, Oelgeschlager, Gunn y Hain, pp. 91-95.

Buckley, P. y Casson, M. (1988): “A theory of cooperation in international business”, en Contractor, F. y Lorange, P. (eds.) Cooperative Strategies in International Business, Lexington MA, Lexington Books, pp. 31-53.

Burgers, W. P., Hill, C. W. L. y Kim, W. C. (1993): “A theory of global strategic alliances: the case of the global auto industry", Strategic Management Journal, 14, pp. 419-432.

Bradley, M. F. (1985): "Market an Internal Organization in Exporting for SMEs”, presentado en Developing Markets for New Products and Services Through Joint Exporting by Innovative SMEs Seminar, Commision of the European Communities, Luxembourg, march, pp. 6-7.

Brockner, J., Siegel, P.A., Daly, J. P., Tyler, T. y Martin, C. (1997): "When trust matters: The moderating effect of outcome favorability", Administrative Science Quarterly, 42, pp. 558-583.

Cabeza, M. y Martínez, E. (2004): "La política comercial argentina y los consorcios de exportación”, Serie Docencia, no 77, pp. 5-22.

Castro González, P. (2010): La política exportadora de las empresas manufactureras andaluzas de carácter familiar, Tesis Doctoral, Universidad de Córdoba, pp. 103-124.

Castro, M. y Moneu, I. (1993): “Los Consorcios de Exportación”, Información Comercial Española, no 718, pp. 63-78.

Contractor, F. y Lorange, P. (1988): "Why should firms cooperate? The strategy and economics basis for cooperative ventures", en Contractor, F. and Lorange, P. (eds) Cooperative Strategies in International Business, Lexington MA, Lexington Books, pp. 17-31.

Coyle-Shapiro, J.A.M. y Morrow, P. C. (2003): "The role of individual differences in employment adoption of TQM orientation”, Journal of Vocational Behaviour, 62, pp. 320-340.

Dirk, K. T. y Ferrin, D. L. (2002): "Trust in leadership: Meta-analytical findings and implications for research and practice”, Journal of Applied Psychology, 87, pp. 611628.

Duyster, G. y Lokshin, B. (2001): "Determinants of Alliance Portfolio Complexity and Its Effect on Innovative Performance of Companies”, Journal of Product Innovation Management, 28 (4), pp. 570-585.

D'Aunno, T. A. y Zuckerman, H. S. (1987): “A Life-Cycle Model of Organizational Federations: The Case of Hospitals", Academy of Management Review, volumen 12, $\mathrm{n}^{\mathrm{o}} 2$, pp. 534-545. 
Errecart, V. (2013): "Marco Teórico para el abordaje del estudio de los consorcios de exportación", Serie de documentos de economía regional, Escuela de Economía y Negocios, Universidad Nacional de San Martín, noviembre, no 21, pp. 5-20.

Fernández, P. M. (2014): "La experiencia italiana en consorcios de exportación: un aporte para las PyMEs argentinas”, Maestría en Negocios Internacionales, Universidad de Ciencias Sociales y Empresariales, Buenos Aires (Argentina), pp. 2-8.

Fernandez Sánchez, E. (1991): “La cooperación empresarial”, Información Comercial Española, $\mathrm{n}^{\mathrm{o}}$ 693, pp. 25-38.

Fulmer, C. A., y Gelfand, M. J. (2012): "At what level (and in whom) we trust: Trust across multiple organizational levels", Journal of Management, 38, pp. 1167-1230.

Galaskiewicz, J. (1985): “International relations”, Annual review of Sociology, 11, pp. 281304.

Gallo, M.A., Ariño, A., Máñez, I. y Cappuyns, K. (2002): Internacionalización vía alianzas estratégicas en la empresa familiar, Barcelona (Spain), IESE.

Gao, L., Janssen, O. y Shi, K. (2011): "Leader trust and employee voice: the moderating role of empowering leader behaviours", Leadership Quarterly, 22, pp. 787-798.

García Canal, E. (1996): "Contractual form in domestic and international strategic alliances", Organization Studies, vol. 17, nº 5, pp. 773-794.

Gebhard, T. A. (1987): "Export Joint Ventures as a Tool for Small Business", Business Forum, vol. 12, n 4, pp. 26-29.

Ghauri, P., Lutz, C. y Tesfom, G. (2003): "Using networks to solve export-marketing problems of small- and medium-sized firms from developing countries", European Journal of Marketing, 37 (5/6), pp. 728-752.

Gomes-Casseres, B. (1994): "Group versus group: how alliance networks compete", Harvard Business Review”, 72 (4), pp. 62-74.

Gulati, R. y Singh, H. (1998): "The architecture of cooperation: Managing coordination costs and appropiation concerns in strategic alliances", Academy of Management Journal, vol. 38, pp. 85-112.

Gulati, R. y Singh, H. (1999): "Cooperative or controlling? The effects of CEO-board relations and the conten of interlocks on the formation of Joint Ventures", Administrative Science Quarterly, vol. 44, n 3, pp. 473-506.

Fulmer, C.A. y Gelfand, M.J. (2012): “At What Level (and in Whom) We Trust: Trust Across Multiple Organizational Levels", Journal of Management, vol. 38, n 4, pp. 11671230.

Jacobsohn, G. (1997): La internacionalización de las Pymes argentinas en un contexto de globalización: los consorcios de exportación, Consejo Profesional de Ciencias Económicas, Ciudad de Buenos Aires.

Harrigan, K. R. (1988): "Strategic alliances and partner asymmetries", en Contractor, F. y Lorange, P. (eds.): Cooperative Strategies in International Business, Lexington MA, Lexington Books, pp. 205-226.

Hennart, J. (1991): "The transaction costs theory of joint ventures: an empirical study of Japanese subsidiaries in the United States", Management Science, 37, pp. 483-497.

Hovi, N. (1994): "Internationalizing Subcontractors: Is Co-operation an Alternative?" en Veciana, J.M. (ed.): Internationalization Networks and Strategy, England: Avebury, pp. 359-379. 
Kets de Vries, M. (1993): "Lo bueno y lo malo de las empresas de titularidad familiar", Harvard Deusto Business Review, 4, pp. 32-44.

Kets de Vries, M. (1996): Family Business: Human Dilemmas in the Family Firm London: Thomson Business Press, pp. 5-45.

Kim, J. y Parkhe, A. (2009): "Competing and Cooperating Similarity in Global Strategic Alliances: an Exploratory Examination”, British Journal of Management, vol. 20, pp. 363-376.

Lanzara, R., Varaldo, R. y Zagnoli, P. (1991): "Public Support to Export Consortia: The Italian Case", en Seringhaus, F. H. y Rosson, P. J. (eds.): Export Development and Promotion: The Role of Public Organizations, Kluwer Academic Publishers, pp. 217241.

Lapidot, Y., Kark, R., y Shamir, B. (2007): "The impact of situational vulnerability on the development and erosion of followers; trust in their leader", Leadership Quarterly, 18, pp. 16-34.

Lim, J., Sharkey, T. W. y Kim, K. L. (1991): “An empirical test of an export adoption model”, Management International Review, 31(1), pp. 51-61.

López Navarro, M.A. (2014): "Acuerdos de cooperación en el ámbito exportador: incidencia de la orientación temporal de los socios sobre el desempeño", Innovar: revista de ciencias administrativas y sociales, vol. 24, no 52 (abril-junio), pp. 19-30.

López Navarro, M.A. (2001): "Caracterización de los consorcios de exportación en el sector agroalimentario español”, Revista española de estudios agrosociales y pesqueros, $\mathrm{n}^{\circ}$ 193, pp. 143-168.

López Navarro, M.A. y Camisón Zornoza, C. (1999): "Los consorcios de exportación como estrategia de cooperación un análisis contingente con el proceso exportador de la PYME", Dirección y organización: Revista de dirección, organización y administración de empresas, $\mathrm{n}^{\circ}$ 22, pp. 5-13.

Lu, J. W. y Beamish, P. (2001): "The Internationalization and Performance of SMEs" Strategic Management Journal, vol. 22, $\mathrm{n}^{\mathrm{o}}$ 6/7, Special Issue: Strategic Entrepreneurship: Entrepreneurial Strategies for Wealth Creation, pp. 565-586.

Madjar, N. y Ortiz-Walters, R. (2008): "Customers as contributors and reliable evaluators of creativity in the service industry", Journal of Organizational Behaviour, 29, pp. 949966.

Martínez Carazo, C. (2003):"Proceso del desarrollo exportador de las empresas industriales españolas que participan en un consorcio de exportación: un estudio de caso", Documents de Treball (Universitat Autònoma de Barcelona. Departament d'Economia de l'Empresa ), nº 6, pp. 2-24.

Meier, M. (2011): "Knowledge Management in Strategic Alliances: A Review of Empirical Evidence", International Journal of Management Review, vol. 13, pp. 1-23.

Moran, P. (2005): "Structural vs relational embeddedness: Social capital and managerial performance", Strategic Management Journal, 26, pp. 1129-1151.

Morgan, R. M. y Hunt, S. D. (1994): "The commitment-trust theory of relationship marketing", Journal of Marketing, 58 (julio), pp. 20-38.

Nakos, G. y Brouthers, K. D. (2008): "International alliance commitment and performance of small and medium-size enterprises: The mediating role of process control", Journal of International Management, 14, pp. 124-137. 
Oliver, C. (1990): "Determinants of interorganizational relationships: integration and future directions", Academy of Management Review, 15, pp. 241-265.

ONUDI (2004): Desarrollo de conglomerados y redes de PYME: Guía de los consorcios de exportación, Organización de las Naciones Unidas para el Desarrollo Industrial y Federexport, Viena, pp. 5-65.

Ortega Giménez, A. (2009): "Vías de colaboración en el comercio internacional: el contrato de "joint venture", Iuris: Actualidad y práctica del derecho, nº137, pp. 51-55.

Pesämaa, O. y Hair, J. F. (2007): "More than friendship is required: an empirical test of cooperative firms strategies", Management Decision, 45 (3), pp. 602-615.

Premeaux, S. y Bedeian, A. G. (2003): "Breaking the silence: the moderating effects of selfmonitoring in predicting speaking up in the workplace", Journal of Management Studies, 40, pp. 1537-1562.

Provan, K. (1984): "Interorganizational Cooperation and Decision Making Autonomy in a Consortium Multihospital System”, The Academy of Management Review, vol. 9, $\mathrm{n}^{\mathrm{o}} 3$ (jul.), pp. 494-504.

Poutziouris, P.Z. (2001): "The views of family companies on venture capital: empirical evidence from the UK small to medium-size enterprising economy", Family Business Review, 14(3), pp. 277-291.

Renart, L1. (1996): "Diez pasos estratégicos para la gestación de un consorcio de exportación", Harvard-Deusto Marketing y Ventas, septiembre-octubre, pp. 43-50.

Renart, Ll. (1997): Consorcios para la exportación: en busca del mejor aliado, volumen 16 de la Biblioteca IESE de Gestión de Empresas, Ediciones Folio, S.A., Barcelona, pp. 50-95.

Renart, Ll. (1999): “Consorcios de exportación y otros tipos de alianzas estratégicas entre empresas", Boletín Económico de ICE, Información Comercial Española, nº 2627, pp. 1001-1016.

Renart, Ll. (2002): "El ciclo de la participación de una empresa en un consorcio de exportación”, IESE Business School, Universidad de Navarra, Documento de investigación DI-477, octubre.

Reve, T. (1990): "The firm as a nexus of internal and external contracts", en M. Aoki, B. Gustafsson y O. Williamson (eds.), The Firm as a Nexus of Treaties SAGE, pp. 133161.

Reve, T. (1992): "Horizontal and vertical alliances in industrial marketing channels", Advances in Distribution Channel Research, 1, pp. 235-257.

Rosanas, J. (2008): "Beyond economic criteria : A humanistic approach to organizational survival", Journal of Business Ethics, 78, pp. 447-462.

Sánchez de Pablo González del Campo, J.D. (2007): "Clasificación de los acuerdos cooperativos en función de su estructura organizativa: importancia de las Joint ventures", Empresa global y mercados locales: XXI Congreso Anual AEDEM, Universidad Rey Juan Carlos, Madrid, 6,7 y 8 de junio / coord. por Carmelo Mercado Idoeta, vol. 2, comunicaciones, pp. 1-12.

Skarmeas, D., Karsikeas, C. y Schelegelmich, B. (2002): "Drivers of commitment and its impact on performance in cross-cultural buyer-seller relationships: the importer's perspective”, Journal of International Business Studies, 33, pp. 757-783.

Thorelli, H. (1986): "Networks : Between markets and hierarchies", Strategic Management Journal, 7 (1), pp. 37-51. 
Ullmann, R (1999: 23): PyMEs formas asociativas de comercialización y exportación, Ed. Desalma, Buenos Aires.

UNIDO (2009): "The Strategic Management of Export Consortia:An analysis of the experience of UNIDO in Morocco, Peru, Tunisia and Uruguay", Industrial Policy and Private Sector Development Branch Programme, pp. 1-6.

Vallejo Martos, M.C. (2008): "Is the Culture of Family Firms Really Different? A valuebased model for its survival through generations", Journal of Business Ethics, 81(2), pp. 261-279.

Welch, L. y Joynt, P. (1987): “Grouping for Export: an Effective Solution?”, en Reid S.D. y Rosson, P. (eds.): Managing Export Entry and Expansion, New York: Praeger, pp. 5470.

Zhao, Z., Xia, M. yShaw, J (2007): "An integrated model of consortium-based e-business standardization: collaborative development and adoption with network externalities", Journal of Management Information Systems, 23 (4), pp. 247-271. 